\title{
Geopoética dos sentidos, a/r/tografia e o patrimoniável em chave descolonial: por uma poética do Sul
}

\author{
Geopoetics of senses, a/r/tografy and "patrimoniable" in \\ decolonial key: for a poetics of the South
}

\section{Geopoética de los sentidos, a/r/tografía y lo patrimo- niable en clave decolonial: por una poética del Sur}

\author{
Claudio Andrés Barría Mancilla * \\ Universidade Federal do Estado do Rio de Janeiro, Brasil
}

https://doi.org/10.22409/poiesis.v20i34.38312

RESUMO: O presente artigo propõe uma releitura dos conceitos de aura da arte (BENJAMIN), memória e identidade no contexto latino-americano em chave descolonial, isto é, tendo a diferença colonial como lócus de enunciação, para sentipensar dispositivos de descolonização da memória e da escrita, em diálogo com os conceitos de geopoética dos sentidos e do patrimoniável (AMARAL) a partir de experiências a/r/tográficas vivenciadas em mergulhos poéticos no lugar, como mediação cultural e ativação de territórios realizadas na cidade do Rio de Janeiro, que questionam sobre outros patrimônios possíveis, contra o desperdício da experiência (SANTOS, 2010), em alinhamento a uma poética do Sul.

PALAVRAS-CHAVE: memória; lugar; patrimoniável; geopoética dos sentidos; poética do Sul

\footnotetext{
* Claudio Andrés Barría Mancilla é doutor em Educação pela UFF e docente no IVL/Centro de Letras e Artes/UNIRIO. E-mail: clanbarria@gmail.com. Orcid: http://orcid.org/0000-0001-8036-3124
} 
ABSTRACT: This article proposes a re-reading of aura (BENJAMIN) of art, memory and identity concept in Latin American context in a decolonial key, that is, having the colonial difference as locus of enunciation, to feel-think devices of decolonization of memory and writing, in dialogue with the concepts of geopoetics of the senses and the patrimony (AMARAL) from $a / r /$ tographics experiences in poetic dives in place, such as cultural mediation and activation of territories held in the city of Rio de Janeiro, which question about other possible heritages, against the waste of experience (SANTOS, 2010), in alignment with a poetics of the South.

KEYWORDS: memory; patrimoniable; geopoetics of the senses; poetics of the South

RESUMEN: Este artículo plantea una relectura de los conceptos de aura del arte (BENJAMIN), memoria e identidad en el contexto latinoamericano en clave decoIonial, o sea, teniendo la diferencia colonial como locus de enunciación, para senti-pensar dispositivos de descolonización de la memoria y de la escrita, en diálogo con los conceptos de geopoética de los sentidos y lo patrimoniable (AMARAL), a partir de experiencias $a / r /$ tográficas vivenciadas en inmersiones poéticas en el lugar, como mediación cultural y activación de territorios realizadas en la ciudad de Río de Janeiro, que cuestionan sobre otros patrimonios posibles, contra el desperdicio de la experiencia (SANTOS, 2010), alineada a una poética del Sur.

PALABRAS CLAVE: memoria; patrimoniable; geopoética de los sentidos; poética del Sul

Citação recomendada:

MANCILLA, Claudio Andrés Barría. Geopoética dos sentidos, a/r/tografia e o patrimoniável em chave descolonial: por uma poética do Sul. Poiésis, Niterói, v. 20, n. 34, p. 87-108, jul./dez. 2019. [https://doi.org/10.22409/poiesis.v20i34.38312]

Claudio Andrés Barría Mancilla, Geopoética dos sentidos, a/r/tografia e o patrimoniável em chave.... 


\section{Geopoética dos sentidos, a/r/tografia e o patrimoniável em chave descolonial: por uma poética do Sul}

O presente artigo se insere no esforço coletivo de pensar uma estética descolonial, reflexão iniciada em 2003 pelo artista afrocolombiano Adolfo Alban Achinte no contexto do Projeto modernidade / colonialidade / des-colonialidade ${ }^{1}$ em torno ao debate sobre a matriz de poder colonial: qual o lugar da estética na matriz colonial? Precedido pelos estudos sobre a colonialidade do po$\mathrm{der}^{2}$, do saber e do ser, o debate foi abordado por Walter Mignolo no artigo Aiesthesis decolonial (2010) e por Gomez e Mignolo (2012) no texto de abertura da exposi- ção Estéticas descoloniais, em que propõem, a partir da prática artística e do debate em torno das obras, "avançar na conceituação da descolonização da estética e a libertação da aiesthesis (o sentir)"3.

O desafio proposto implica, seja na crítica, na indagação ou no fazer, operarmos um giro epistêmico à procura de categorias e critérios outros, ancorado no próprio quefazer criativo. Um ato de desobediência epistêmica que nos permita tanto indagar pelo sentido e o lugar da criação artística na re- 
gião e seu legado, como produzir estratégias e abordagens metodológicas que operem como dispositivos de resgate de uma experiência ${ }^{4}$ negada pela colonialidade; mediar a memória inscrita na paisagem, no uso do espaço, nos corpos e nas práticas sociais, assim como os processos de produção estética nos/dos territórios a partir da noção de lugar. É preciso partir do Sul, em direção ao Sul, como nos convida Boaventura de Sousa Santos (SANTOS; MENESES, 2010).

A sutil teia em que é tecida nossa produção somente a vivência sensível consegue desvendar. Todavia, esse complexo entrelaçar intersubjetivo é decerto atravessado pelo espaço que habitamos e pelas pegadas que nele deixamos. Somos no lugar e, como nos lembra Milton Santos (1997), cada lugar é, a seu modo, o mundo; nele vivenciamos e recriamos sentidos de pertença; é a partir do lugar que podemos perceber o mundo e sua totalidade, tornando-nos conscientes da nossa experiência sensível; e é, nesse emaranhado de trajetórias que confluem e desaguam, que criamos.

A pureza da nossa arte é a mescla, porque híbrida é a ontologia do nosso ir sendo e múltiplas são as fontes das que bebe a nossa ancestralidade, nossa vida em relação neste lugar do mundo, nossa América. O sermos latino-americanos, que significa sermos na nossa América, não constitui uma essência, mas um ser aqui e, assim, um ver desde cá. Mas um ser em movimento e relação - e, assim, produtor do espaço habitado, de identidades e de sentidos éticos e estéticos e de formas específicas de lidar com os modos de produção da vida impostos pelo capital na modernidade/colonialidade - isto é, um vir a ser no lugar, atrelado a um topoi.

Como vir a ser tópico e em relação, é o produto de diversas trajetórias coletivas que fazem com que, em diferentes esferas da espacialidade, esta conceituação não essencialista da identidade e sua potência possa ser aplicada a cada identidade local decorrente de cada trajetória coletiva de luta e/ou socialização, mas também das culturas em relação (povos originários, remanescentes de quilombos etc.) ou mesmo de grupos não territorializados (como as redes de coletivos articulados via web). 


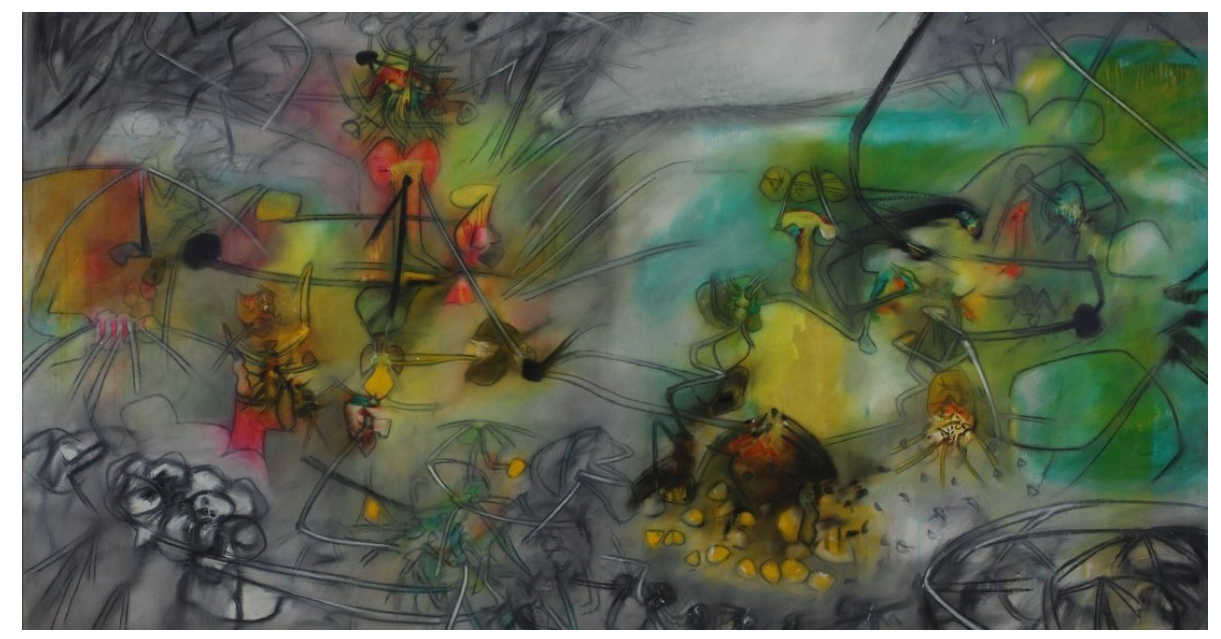

Fig. 1 - Roberto Matta, Nacimiento de América (detalhe), 1952. Coleção MAC, Universidad de Chile, Santiago

Poiésis, Niterói, v. 20, n. 34, p. 87-108, jul./dez. 2019. 
Para Silviano Santiago - no contexto de um debate estético sobre o que ele definiu como o "entre-lugar" da cultura latinoamericana -, a nossa fala, a palavra enunciada desde a América latina, é uma fala contra, pois o só ato de enunciar desde cá, e com autenticidade, é uma negação do cânone imposto (SANTIAGO, 1978). Isto é, por ser a nossa enunciação, na diferença colonial, necessariamente uma enunciação "contra", pelo simples ato de ser, denuncia o silenciamento e, ao mesmo tempo, anuncia uma existência negada como potência, subalternizada.

É a memória o elemento aglutinador, reordenador e redefinidor desse imaginário da identidade como dispositivo central do sujeito da transformação social. Deixa-se entrever, ao longo de nossa história e costurando-a, uma identidade rebelde que nos define na diversidade, e produz, cria, rexiste e semeia. A memória dos vencidos e a expressão estética hibridizada explícita na cultura viva nos territórios subalternizados dos grandes centros urbanos constituem nodos dessa identidade rebelde, heteronímica $^{5}$ e pluriversal, cuja expressividade e potência criativa estão na base de um projeto de descolonização da educação e da ar- te. Somos, como diria Oswald de Andrade, Escola e Floresta. É esta nossa poiese.

\section{[A pureza híbrida de uma cultura regurgi- tada e a descolonização da memória na re- tomada do vínculo com o fazer criativo da nossa América: Escola-Floresta]}

A descolonização da memória torna-se fundamental para um realinhamento geopoético ao Sul, a (re)construção de narrativas sensíveis a partir da diferença colonial (MIGNOLO, 2003). Retomando a poética da Escola-Floresta e do Manifesto antropofágico de Oswald de Andrade e a de Torres Garcia ("nuestro Norte es el Sur") entre tantos na história da nossa América, colocamo-nos o desafio de senti-pensar a produção de dispositivos de escrita e memória voltados para sua descolonização, no movimento de religar nossa memória/ação criativa com a nossa heteronímica unicidade estética, viva no lugar.

O tempo longo da colonialidade do poder que, como nos lembra Quijano (2001) ainda não concluiu, significou para "índios", "negros" e "mestiços" - segundo as categorias coloniais - a experiência de se verem presos 


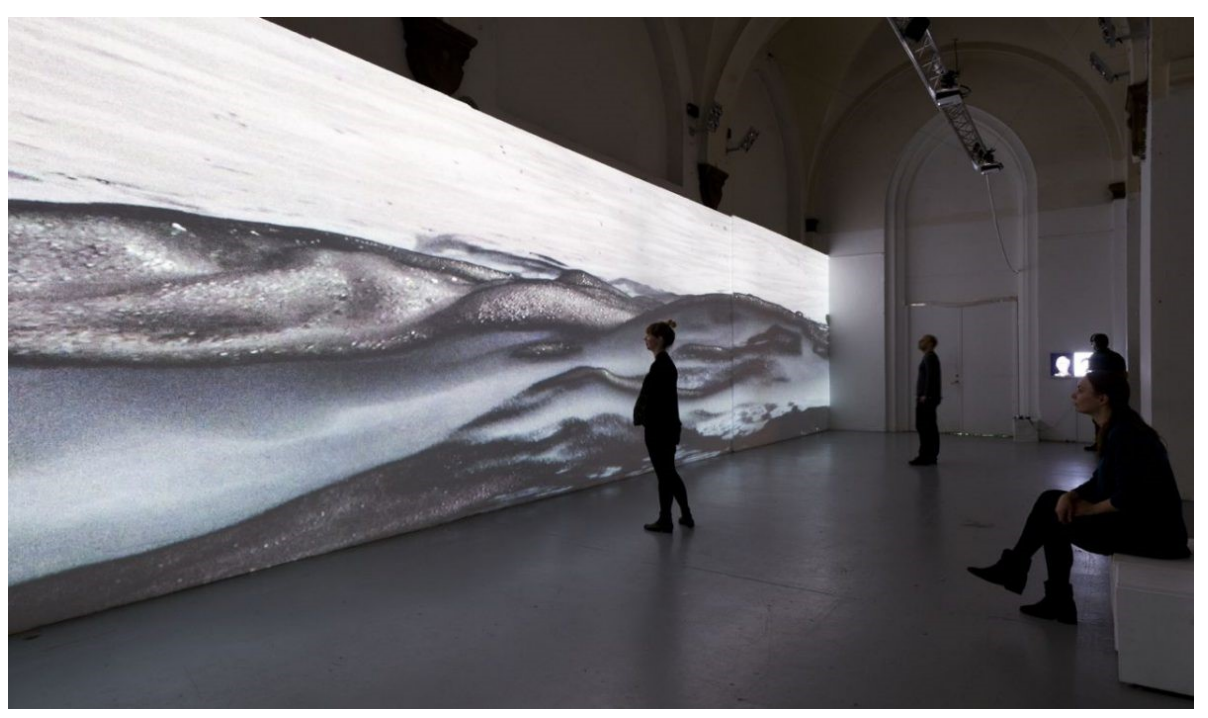

Fig. 2 - Jeannette Ehlers, Waves, 2014.

Instalação, Nikolaj Kunsthal, Copenhagen, Dinamarca

Poiésis, Niterói, v. 20, n. 34, p. 87-108, jul./dez. 2019. 
entre o padrão epistemológico próprio e o padrão eurocêntrico, forçados a uma dupla consciência (DU BOIS, 1999) que se transformou em racionalidade instrumental ou tecnocrática (QUIJANO, 2001). Um certo senso comum acadêmico, considerando o fato destas populações terem sido submetidas por tantos anos a tamanha alienação, acredita que elas, fora algumas expressões remanescentes de culturas arcaicas (logo desprovidas de atualidade estética e política), apenas se limitariam à imitação dos cânones eurocêntricos. Assim, as diferenças entre os cânones estéticos hegemônicos na modernidade/colonialidade e as produções simbólicas dos colonizados e seus herdeiros, dever-se-iam a erros ou incompetências na sua arte de imitar.

Todavia, não há apenas imitação e reprodução nas culturas subalternas na nossa América, mas a constante subversão dos cânones impostos. Para Quijano,

\section{A expressão artística das sociedades coloniais dá clara conta dessa contínua subversão dos padrões visuais e plásticos, dos temas, motivos e imagens de alheia origem, para poder expressar a sua pró- pria experiência subjetiva, se não a prévia, original e autônoma, sim, entretanto, uma nova, dominada}

sim, colonizada sim, porém subvertida o tempo todo, convertida assim em espaço e modo de resistência. ${ }^{6}$

Esta condição de reinvenção de padrões estéticos devido ao seu desenvolvimento em relação atravessa praticamente toda a história da arte e da cultura da nossa América e pode ser facilmente observada muito antes dos movimentos que, no século $X X$, assumiram abertamente essa postura.

No Brasil, o movimento antropofágico, assim como, na música popular, a Tropicália e mais tarde o Mangue bit, são exemplos paradigmáticos de vanguardas artísticas e intelectuais que perceberam esta condição. O movimento plasmado no Manifesto Antropofágico de Oswald de Andrade, em 1928, usa a antropofagia como metáfora para significar essa atitude estético-cultural de "devoração" e assimilação crítica dos valores culturais estrangeiros transplantados ao Brasil, bem como realçar elementos e valores culturais internos que foram reprimidos pelo processo de colonização: "Só a ANTROPOFAGIA nos une. Socialmente. Economicamente. Filosoficamente. [...] Já tínhamos o comunismo. Já tínhamos a língua surrealista. A idade de ouro". (ANDRADE, 1976 $)^{7}$

Claudio Andrés Barría Mancilla, Geopoética dos sentidos, a/r/tografia e o patrimoniável em chave.... 
Todavia, a fonte da qual beberam estes movimentos de vanguarda tem uma longa tradição no continente. A subversão dos padrões estéticos, sua reapropriação "desde cá" para a produção de uma arte original, defendida por nomes como Hélio Oiticica, Mario de Andrade, Oswald de Andrade, os tropicalistas ou Haroldo de Campos, entre tantos outros, pode ser conferida nas danças populares, nas vestes, nos adereços e nas festas de brasileiros, antilhanos, mexicanos ou no planalto andino. Do mesmo modo, essa subversão dos padrões pode ser observada na obra do mineiro Aleijadinho ou na monumental igreja de Potosí, nos quadros da escola de Quito e Cuzco e mais recentemente nos murais dos mexicanos Siqueiros, Rivera, Orozco, como também, e de um modo diverso, nas obras de Guayasamin e Portinari, como também na obra literária de Garcia Marquez, Carpentier, Lezama Lima e Guimarães Rosa, para citar alguns dos mais expressivos.

Do mesmo modo, e por mais que custem a aceitá-lo os puristas defensores da tradição, esta característica de reinvenção profundamente criativa, esta postura culturalmente antropofágica, continua presente no fazer da cultura popular nas periferias dos grandes centros. Não é, acaso, um ato antropo- fágico de subversão estética o chamado Funk Carioca? No dizer do compositor tropicalista Caetano Veloso,

\section{Da eleição do repertório de hits se dando de forma totalmente independente da programação radio- fônica e dos interesses das gravadoras à predomi- nância da batida umbanda-maculelê sobre o Mia- mi bass, o funk carioca é uma história de liberdade inventiva cuja importância ainda havemos de saber reconhecer. ${ }^{8}$}

De um modo outro, talvez uma das mais prolíficas fontes de produção estética e simbólica da cultura popular da América latina e do Caribe, como expressão da sua implícita subversão cultural, encontre-se nos cultos, rituais, festas e nas mais diversas práticas religiosas de um cristianismo subvertido de sentidos ao ponto de reinventá-lo profundamente, seja no sincretismo religioso, seja nos modos e na estética de uma religião que, até então, não aceitava sequer a palavra vernácula nem os instrumentos musicais, que dirá as danças ou quaisquer expressões do corpo em transe. Para os modernistas,

Nunca fomos catequizados. Vivemos através de um direito sonâmbulo. Fizemos Cristo nascer na Bahia. 
Ou em Belém do Pará. Mas nunca admitimos o nascimento da lógica entre nós. [...] Nunca fomos catequizados. Fizemos foi 0 Carnaval. 0 índio vestido de senador do Império. Fingindo de Pitt. Ou figurando nas óperas de Alencar cheio de bons sentimentos portugueses. (ANDRADE, 1976)

Todavia, o espírito do Manifesto Antropofágico, absorvido pela narrativa da normatividade colonial hegemônica e sua noção eurocêntrica de exotismo, em tempo que inserido como fragmento de memória no contexto da saturação imagética potenciada pela tecnociência midiática, costuma ser dissociado de uma leitura dinâmica da potência de subversão de cânones estéticos inerente à cultura da nossa América profunda, tirando assim sua atualidade política. Aqui, como em toda América latina, a colonialidade do poder continua operando na perpetuação do ocultamento e/ou da subalternização das culturas ditas populares.

Se lançarmos mão, para ajudar em nossa reflexão, do conceito de aura proposto por Walter Benjamin (1985) no seu já clássico texto $A$ obra de arte na era sua reprodutibilidade técnica, mas assumindo um necessário giro epistêmico, podemos perceber o caráter revolucionário da aura da obra de arte de um modo diferente ao apontado por ele (1985): uma espécie de transmutação do próprio conceito de aura. Na leitura benjaminiana, na Europa da primeira metade do século XX, a necessidade de politizar a arte, em contraposição à estetização da política em um sentido fascista, o levou a advogar pela reprodutibilidade e pela eliminação do conceito de originalidade. Da mesma maneira, neste século XXI emerge ante nós a potência vital e rebelde da aura da arte na periferia-mundo, intimamente ligada à cultura popular subalternizada, como constatação da vida fora das fronteiras da monocultura do mercado e sua estese modernocolonial. O elo se encontra na potência criativa de apropriação e de subversão que possui a arte popular, múltipla, inventiva, ancestral e antropofágica. Potência esta que Ihe permite não apenas sobreviver e resistir, mas criar onde menos se espera: rexistir.

Memória negada ou reificada pela cultura dominante. O entendimento da aura como elemento essencial da historicidade e unicidade de um determinado grupo subalternizado aparece como potência de afirmação/negação dialética da identidade. Negação do que somos, como cultura "folclorizada"

Claudio Andrés Barría Mancilla, Geopoética dos sentidos, a/r/tografia e o patrimoniável em chave.... 


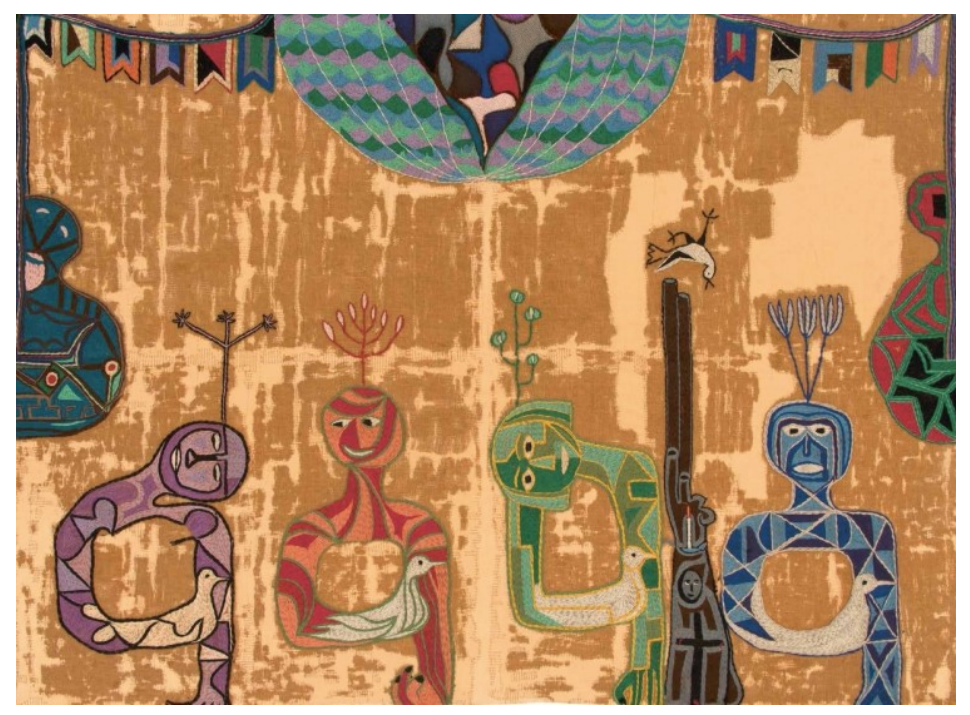

Fig. 3 - Violeta Parra, Contra la Guerra, 1962. Museo Violeta Parra, Santiago, Chile 
e restrita a um suposto passado préindustrial; e afirmação do nós negado, ao assumir a alteridade, na que continuamos sendo a partir do momento em que fazemos. E fazemos de uma determinada forma que muda, porém, conservando o modo de ser aurático das nossas tradições, isto é, a forma de ser hoje, aqui e agora das trajetórias dos povos. Falamos da existência da produção contínua de um pluriverso simbólico regional e de noções de beleza desde a subalternidade-mundo latino-americana, produto de trajetórias de r-existência e sua memória rebelde, que se configuram, no momento da sua enunciação, em uma estética da ruptura e de subversão dos cânones da modernidade/colonialidade.

Esta compreensão traz implícita uma releitura de conceitos fundamentais para a análise estética, como os de tradição e contemporaneidade. É por estarmos falando a partir de lugares diferentes, de uma história construída na diferença colonial, que o nosso pensamento com relação à tradição se aproxima da visão de José Carlos Mariátegui (1990), para quem a tradição é viva e móvel. É nesse entendimento que afirma,
Criam-na [a tradição] os que a negam para renovála e enriquecê-la. Matam-na os que a querem morta e imóvel, prolongamento do passado num presente sem forças, para nela incorporar seu espírito e nela transfundir seu sangue. (MARIATEGUI,

1990a)

Pensando a tradição como patrimônio e continuidade histórica, Mariátegui diferencia a tradição da concepção aprisionadora do conservadorismo tradicionalista, entendendo que "a tradição é particularmente evocada, e até ficticiamente monopolizada, pelos menos capazes de recriá-la". (MARIATEGUI, 1990a) É também a partir dessa concepção que diferenciamos o conceito de cultura popular dos tantos que a apresentam como resíduo social subalterno. É este o sentido que nos leva a indagar pela aura de r-existência, não nos redutos guetizados onde, pelo mesmo, a tradição possa se ter "preservado", de algum modo reificada, mas sim na hexis corporal das festas em praça pública, na memória recriada pelo ato coletivo, no habitus ${ }^{9}$ de jovens artistas contemporâneos, no seu modo de ocupar o espaço público, de subverter e reinventar a cidade e sua estrutura colonial e, mais além, na memória e na paisagem. 


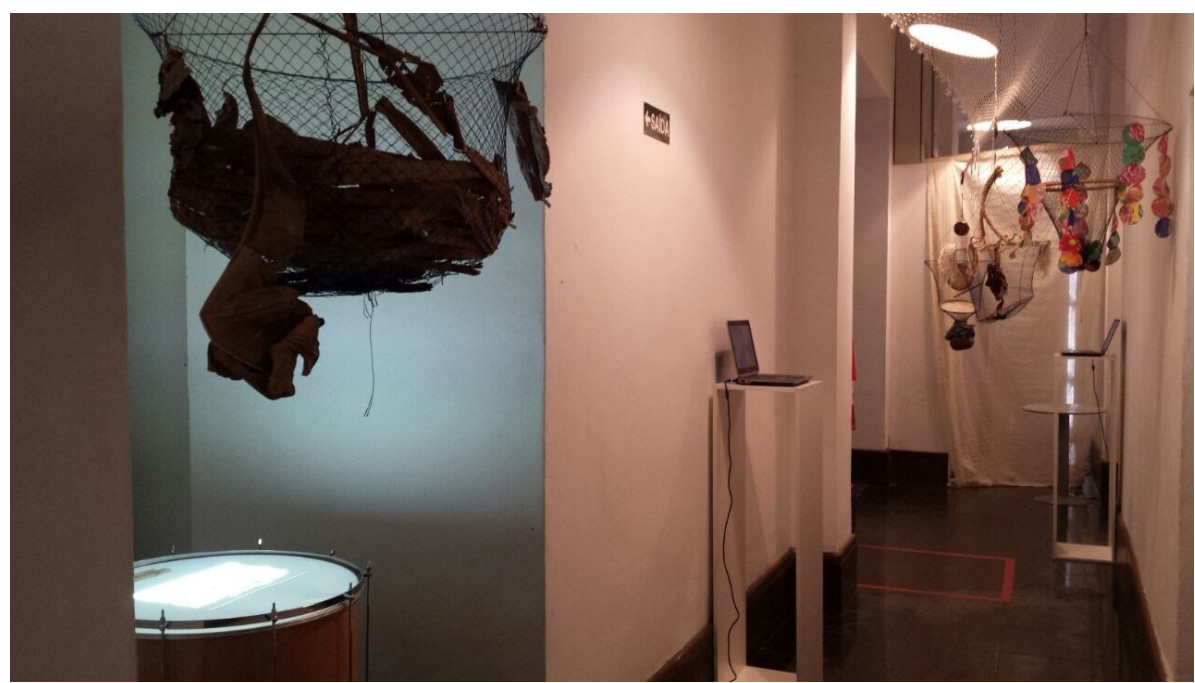

Fig. 4 - Alvarenga, Barría, Lobo, Instalação Rotas da memória EntrePontos cariocas, 2017. Centro Municipal de Arte Hélio Oiticica, Rio de Janeiro 
[Geopoética dos sentidos e a/r/tografia como dispositivos de memória e ativação de lugares/territórios]

Estética, memória e constituição do tecido social formam um entrelaçado indissolúvel. A memória coletiva é estimulada, construída e preservada pelas experiências compartilhadas no cotidiano, pelos sabores e os gestos, laços sociais, políticos e afetivos tecidos em longos e lentos processos de relações copresenciais que vão se redefinindo e constituindo o nós-eu ${ }^{10}$ ontogênico que dá sentidos de existência a uma comunidade comunicativa ${ }^{11}$ ou grupo social, tornandose, em tempo, um aspecto vital da ação criativa, de mediação cultural, social e educativa. As sociedades atuais são complexas, multiformes e atravessadas por tensas relações interculturais que as alargam de sentidos. Porém, o inegável processo de globalização do capital traz consigo a globalização de sua subjetividade, que se torna assim hegemônica. Ativar os territórios a partir das experiências vivenciadas nos lugares em processos de mediação cultural e produção estética (mediação cultural como arte/educação e arte como mediação da memória) se torna parte do fortalecimento da nossa diversidade biocultural, isto é, da vida.
A expressão estética reflete o cotidiano e as relações sociais, econômicas, políticas e bioculturais de um povo ou, de outro modo, suas relações com os processos de produção/reconfiguração e organização do espaço habitado. Desta forma, a indagação estética em interação com os diversos usos do espaço, suas relações afetivas e as práticas estruturadas e estruturantes dos agentes sociais no lugar constitui uma espécie de "buraco de minhoca"12 que permite acessar, na mesma ação performativa, passado, presente e futuro no mesmo movimento em que o espaço urbano é ressignificado por essa ação. Entender o mundo como museu, que articule passado e futuro (AMARAL 2014，2015; MARTIN-BARBERO 1997, 2004), demanda descobrir os dispositivos de ativação da memória e do olhar a partir da experiência vivenciada, do espaço habitado.

Experiências estético performativas de pesquisa co-elabor-ativa realizadas entre os anos 2016 e 2018 junto à artista e pesquisadora Lilian Amaral e ao Instituto de Arte Tear $^{13}$ permitiram-nos perceber esse processo de mediação como um ato arte/educativo solidário. Entendendo memória, cultura e identidade como um entrelaço

Claudio Andrés Barría Mancilla, Geopoética dos sentidos, a/r/tografia e o patrimoniável em chave... 
complexo que articula as espaçotemporalidades humanas, e que podemos acessar a partir do lugar, a estratégia traçada nas citadas experiências buscou interrelacionar, pela interpolação de diversas tecnologias da memória, o que Levy (1993) chamou de "tempos do espírito": a oralidade primária, a escrita e a informática. Buscamos criar assim, dispositivos de criação, captura, reflexão e aprofundamento da experiência. Para isso, de forma transversal e integrada aos processos de mediação no território, as ações de produção co-elaborativa envolveram também plataformas digitais na web, que denominamos Fórum de escrita co-elabor-ativa ${ }^{14}$. Este configurou-se como espaço de pesquisa, criação, compartilhamento e reflexão acerca de percepções e de memória de vivências "andariIhantes", a/r/tografadas coletivamente nos diversos territórios, reais e imaginários. Nas palavras de Amaral,

Espaço de invenção, questionamento e intercâmbio de processos de mediação cultural e artística que opera no campo da educação patrimonial, como forma de construção de narrativas em territórios em transformação. [...] Desta forma, como construção processual, um devir coletivo e flexível, sua configuração seja a do patrimoniável..$^{15}$
O uso desta tecnologia da inteligência (LÉVY), como elo da interface de memória, permitiu o acompanhamento e a intervenção em tempo real por parte de todos os envolvidos. Ao articular experiência/lugar/ tempo/memória/partilha/co-criação, a plataforma operou como um "esticador" do tempo de reflexão/sensibilização/partilha dado nos encontros vivenciados.

Entramos nos territórios por outras dimensões do lugar que passam pelo afeto, pelo uso, pelo inventário, instigados a indagar, "podem as práticas artísticas e de mediação construir lugar/território?"16 O encontro com o outro, no lugar, como espaços estranhados pelo olhar alheio que ali performa e comunga de ritual poético de co-criação; passos, sons, olhares, palavras, mudança, memórias, releituras: a possibilidade de uma escrita co-elabor-ativa a partir da vivência no/do lugar/mundo/museu; uma escrita que articula os três tempos do espírito de modo a colher, junto com o "excedente de visão estética" que o outro tem de mim (BAKHTIN, 2003), a partilha da experiência sensível, sua estesia. Um dispositivo de memória que acha na alteridade do espaço praticado o nexo vital de uma estética de um nós-eu descolonizado. 
A proposta de escrita co-elabor-ativa dialoga intimamente com o campo da a/r/tografia, uma abordagem metodológica baseada na prática artística e na escrita colaborativa, cuja referência é Rita Irwin (2013) ${ }^{17}$. O termo nos fala de uma escrita co-autoral cuja narrativa é tecida pelo a/r/tógrafo e pela comunidade, no lugar. Do mesmo modo, como já apontado, esta ação a/r/tográfica se deu em diálogo com a Geopoética dos Sentidos (AMARAL, 2015, 2015a) baseada na construção co-elabor-ativa que se dá na prática do lugar - "pressupondo, uma performatividade entre corpo e cidade, o dimentos"18

\section{Entre seus objetivos destacamos 0 investigar as transformações urbanas por meio de sistema de cartografia artística/cultural; mapear e analisar, para entender as dinâmicas do lugar; visualizar, para interpretar as articulações diversas que acon- tecem no território; projetar, para traçar novas di- nâmicas produtivas; colaborar, para potencializar e multiplicar as capacidades criativas. ${ }^{19}$}

Toda inscrição na memória do humano é releitura que projeta no tecido social sua narrativa. Para além da tecnologia da inteligência da sua escrita, toda escrita é releitu- ra. Nas sociedades complexas, cidades tensamente interculturais são o contexto de narrativas hegemônicas que obliteram inúmeras memórias. A racionalidade moderna ocidental constitui a urdidura epistêmica que ordena o sistema-mundo, conferindo a ele um sentido único, monocultural, hegemônico. Em nossa sociedade, grafocêntrica e eurocentrada, a história escrita assume certa empatia com aqueles que dominam o código. O tempo da escrita se impõe assim, nos territórios, à oralidade, com superioridade legitimada pela própria condição histórico-social. Todavia, nossa sociedade não é apenas uma, ocidental por antonomásia, como a pretendem suas elites, e não se narra apenas com palavras.

Enquanto o sujeito hegemônico do Ocidente tem a sua história - e, logo, sua leitura das histórias subalternas - contada pelas instituições, pelo direito e mesmo pela ciência (SPIVAK, 2010), registrada nos textos de História (com maiúscula), os subalternos e oprimidos carregam a sua memória/[herança patrimoniável] inscrita no corpo, no gesto, nos atos, nas ações, na paisagem (nos silêncios) e também na palavra - cantada, contada e mesmo escrita. ${ }^{20}$ O lugar de enunciação, a questão da linguagem, as-

Claudio Andrés Barría Mancilla, Geopoética dos sentidos, a/r/tografia e o patrimoniável em chave.... 


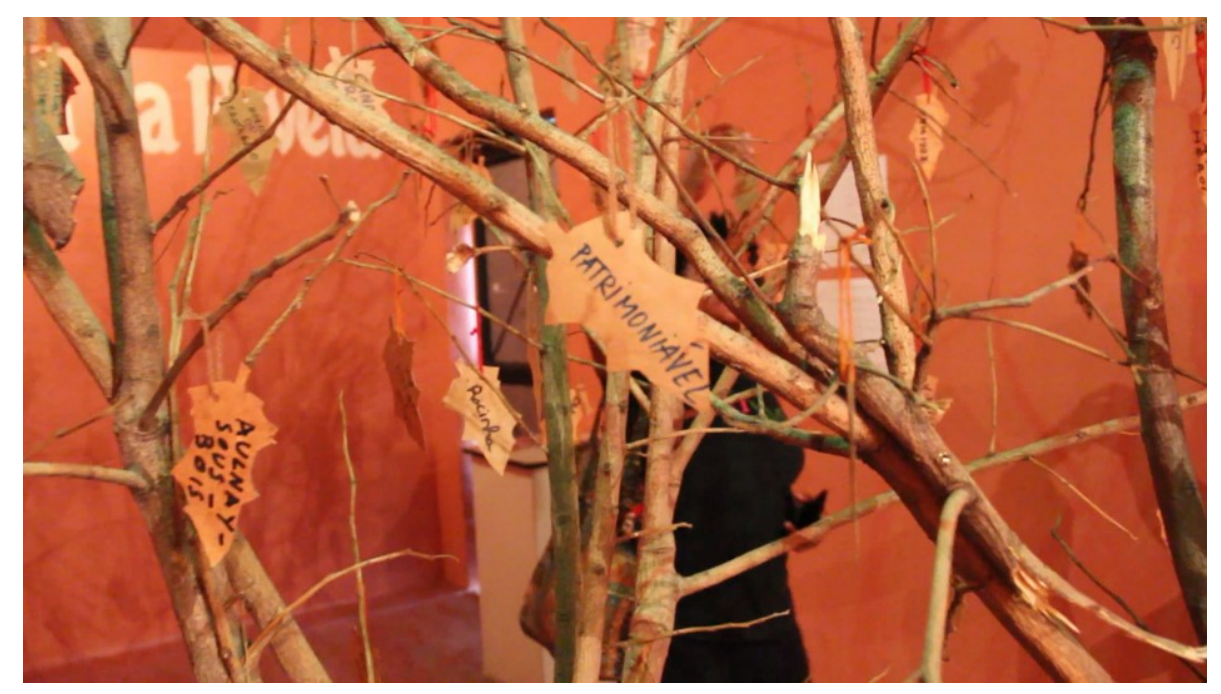

Fig. 5 - Intervenção na exposição Canudos, 2016.

Museu da Maré, Rio de Janeiro

Poiésis, Niterói, v. 20, n. 34, p. 87-108, jul./dez. 2019. 
sim como a possibilidade de reeducarmos o olhar para ler não só palavras, mas também paisagens e corpos, constituem elementos essenciais no desvelamento do outro, do nós-outros, elementos implicados nos dispositivos de memória e da ação $a / r /$ tográfica no sentido proposto.

Descolonizar a escrita e o olhar para enxergar além do que até hoje ela nos conta; articular narrativas outras, em exercício contínuo de desobediência epistêmica (MIGNOLO, 2003). Buscarmos estratégias e abordagens metodológicas que operem como dispositivos de resgate da experiência. Um pensamento fronteiriço como parte de uma geopolítica da sensibilidade e do conhecimento (MIGNOLO, 2011) que abra um diálogo em chave descolonial ao campo da geopoética dos sentidos (AMARAL 2015). Fórum de escrita co-elabor-ativa, ações/ práticas artísticas e vídeo/memória-museu difuso ${ }^{21}$; nossa proposta de ação criativa / indagatória é um movimento de ativação dos territórios, de intervenções performativas que excitem a derme do lugar habitado; a/r/tografar territórios artísticos sensíveis, como cartografias poéticas; é um vir a ser de novas/ancestrais memórias coletivas; (nos) afetar e assim achar os nexos do
Nós-Eu de que nos fala Norbert Elias. Sulear nossas pesquisas. Arte como mediação cultural e social, como ato de reencantamento do espaço. Mediação cultural como ato performativo de arte e de educação.

Mergulhos poéticos no lugar nos incitam a uma reeducação sensível da memória coletiva (visual, auditiva, sinestésica, afetiva, estética), abrindo a experiência sensível a um devir-patrimônio: o patrimoniável. Se o patrimônio é a memória socialmente legitimada, logo, atravessada pela colonialidade do poder e do saber, o patrimoniável é a memória em relação, que emerge como a possibilidade de democratização/descolonização desse processo de legitimação social da arte e da cultura, da memória e da própria herança coletiva em contexto intercultural.

Pensar a totalidade-mundo a partir do lugar, do encontro, em movimento de escrita criativa co-elabor-ativa nos aproxima dos sentidos de uma "poética do Sul". As experiências vivenciadas deixaram resíduos que convergem para o início de uma sistematização do trabalho de mediação cultural como arte/educação entendido como uma pedagogia do patrimoniável, que por ser uma pedagogia da memória ainda não legitima-

Claudio Andrés Barría Mancilla, Geopoética dos sentidos, a/r/tografia e o patrimoniável em chave.... 
da é, se lida em clave descolonial (ou se preferirmos, do Sul global), um ato estético educativo contínuo que sabe ler paisagem e corpos e não apenas os códigos da língua oficial/colonial, alinhado à uma pedagogia da poética do Sul.

\section{Notas}

\begin{abstract}
${ }^{1}$ Nos anos 1990, em decorrência de contribuições em diversos campos do saber ocorridas a partir da segunda metade do século $X X$, como a teoria da dependência, a filosofia da libertação e a teoria do sistema-mundo moderno, surge o chamado "Proyecto Modernidad/ Colonialidad/ Decolonialidad", agrupado em torno do filósofo argentino-mexicano Enrique Dussel, do sociólogo peruano Aníbal Quijano e do semiólogo argentino Walter Mignolo.
\end{abstract}

${ }^{2}$ O Projeto descolonial se reorganiza como campo teórico e político epistêmico a partir de um texto inaugural de Anibal Quijano (1992; e QUIJANO; WALLERTEIN, 1992), intitulado Colonialidad y Moderni-

dad/Racionalidad, onde o sociólogo peruano propõe sua concepção da colonialidade do poder como modo racializado da dominação no sistema-mundo moderno/colonial. Também em 1992, Quijano publica, junto a Wallerstein, Americanity as a Concept or the Americas in the Modern World System, consolidando o conceito de Sistema-mundo moderno/colonial.

${ }^{3}$ Tradução do autor. No original: "avanzar en la conceptualización de la descolonización de la estética y la liberación de la aiesthesis (el sentir)".
${ }^{4}$ No artigo Para além do pensamento abissal: das linhas globais a uma ecologia de saberes" (in SANTOS; MENESES, 2010, p. 31-83), Boaventura de Souza Santos aponta a necessidade de conter o "desperdício da experiência", produto do pensamento moderno ocidental, que descreveu como "Pensamento Abissal".

${ }^{5}$ Sobre a heteronímia da cultura latino-americana e sua potência civilizatória pluriversal, ver BARRIA MANCILLA, 2014, 2017.

${ }^{6}$ QUIJANO 1998. Quijano desenvolve a questão da relação entre Colonialidade do poder, cultura e conhecimento na América Latina em artigo publicado em 1988 no Anuario Mariateguiano, posteriormente revisado e compilado em MIGNOLO, 2001.

${ }^{7}$ Cópia do Manifesto Antropofágico e do Manifesto do Pau-Brasil, de Oswald de Andrade, comentados, disponíveis em

http://www.ufrgs.br/cdrom/oandrade/oandrade.pdf. Último acesso em 10/10/2013.

${ }^{8}$ Disponível em

http://www.caetanoveloso.com.br/blog_post.php?post _id=1455. Acesso pela última vez em 10/10/2013.

${ }^{9}$ Hexis e Habitus são aqui utilizados no sentido proposto por Bourdieu (2000).

${ }^{10}$ Faço referência ao conceito de Nós-Eu como apresentado por Norbert Elias (A Sociedade das Indivíduos. Tradução Vera Ribeiro, Rio de Janeiro, Jorge Zahar, 1994).

${ }^{11}$ Como em Dussel (2007), a partir de Habermas.

${ }^{12}$ Alusão metafórica ao termo (wormhole em inglês), criado pelo físico John A. Wheeler . Ver Annals of Physics, v. 7, n. 3, p. 239-364, jul. 1959.

${ }^{13}$ Refiro-me à experiência Rotas da Memória: entrePontos cariocas, proposta de Museu difuso, transitório e nômade a partir experiências sensíveis da estese em interação vivenciada junto a organizações locais, entendidas como museus do território. O projeto envol- 
veu os Pontos de Cultura e memória Museu do Samba, Museu da Maré, Ecomuseu de Sepetiba e o Instituto de Pesquisa e Memória Pretos Novos - Museu Memorial. Ver AMARAL; BARRIA MANCILLA, 2018, 2018 ${ }^{\text {a }}$; e BARRIA MANCILLA, 2018.

${ }^{14}$ O Fórum de escrita criativa co-elabor-ativa pode ser acessado diretamente na plataforma em que foi sendo produzido, no link http: / /bit.ly/ForumEscrita-Colabor-I

${ }^{15}$ Comentário ao processo de escrita criativa deixado na plataforma do Fórum.

${ }^{16}$ A partir dessa instigação trazida por Lilian Amaral, foi criada uma agenda de visitações/andarilhagens em cada um dos territórios que fizeram parte da experiência. Ver AMARAL; BARRIA MANCILLA, 2018.

${ }^{17}$ Como termo a/r/tography foi concebido com o signo de barra (/), de modo a representar uma certa equidade e coexistência entre as três identidades que o compõem, segundo as siglas do original em inglês - ar-

tist/researcher/teacher: o a/r/tógrafo é então, um artista/pesquisador/educador. A noção de grafia alude a "texto" de modo que, ao estabelecer uma conexão entre arte e texto, alinha as artes junto da narrativa como uma iniciativa conjunta. Ver DIAS; IRWIN, 2013. Ver também:

http://artisticintellect.com/2013/08/05/artographyas-methodology/

${ }^{18} \mathrm{Ver}$

http: / /www.anpap.org.br/anais/2013/ANAIS/simposios /09/Lilian\%20Amaral.pdf

${ }^{19}$ AMARAL, notas ao Fórum de escrita co-elabor-ativa.

${ }^{20}$ BARRIA MANCILLA, 2017.

210 vídeo curta documentário Rotas da Memória, entrePontos Cariocas encontra-se disponível em https://vimeo.com/253543367.

\section{Referências}

AMARAL, Lilian. Cartografias artísticas e territórios poéticos [recurso eletrônico]. São Paulo: Fundação Memorial da América Latina, 2015. Disponível em http://www.memorial.org.br/wp-content/uploads/2017 /01/Cartografias-Art\%C3\%ADsticas-eTerrit\%C3\%B3rios-Po\%C3\%A9ticos.pdf. Acessado pela última vez em 20/12/2017.

AMARAL, Lilian. R.U.A. Geopoética de los sentidos. Comunicação virtual em II Congreso Internacional de Investigación em Artes Visuales ANIAV, 2015a. http://dx.doi. org/10.4995/ANIAV.2015.1053. Acessado em 22/12/2017.

AMARAL, Lilian; BARRIA MANCILLA, Claudio. Rotas da Memória: EntrePontos cariocas [recurso eletrônico], IAT, Rio de Janeiro, 2018. Disponível em http://institutotear.org.br/e-book_rotas_da_memoria/.

AMARAL, Lilian; BARRIA MANCILLA, Claudio. Narrativas da Memória: A Cidade como Museu: Conectividade, práticas artísticas e museologia social contemporânea. In ROCHA, Cleomar (Org.). Anais do V Simpósio Internacional de Inovação em Mídias Interativas. Goiânia: Media Lab / UFG, 2018a.

BARBOSA, Ana Mae; COUTINHO, Rejane Galvão (Org.). Arte/educação como mediação cultural e social. São Paulo: Editora UNESP, 2009.

BARRIA MANCILLA, Claudio. Rotas da Memória entrePontos cariocas, um museu difuso na poética do Sul. In AMARAL, Lilian;

Claudio Andrés Barría Mancilla, Geopoética dos sentidos, a/r/tografia e o patrimoniável em chave.... 
MENDES TOJO, Joselaine. Rede de Redes diálogos e perspectivas das redes de educadores de museus no Brasil [recurso eletrônico]. São Paulo: ACAMPortinari, 2018. Disponível em https://www.sisemsp .org.br/redederedes.

BARRIA MANCILLA, Claudio. Memória, imaginário descolonial e aura da arte e da cultura popular na nossa América. In CARMO CRUZ, Valter do (Org.). Geografia e Giro descolonial. Rio de Janeiro: Letra Capital, 2017, p. 345-367.

BARRIA MANCILLA, Claudio. Pela poética de uma pedagogia do Sul, diálogos e reflexões em torno de uma filosofia da educação descolonial ... Tese de Doutorado, Faculdade de Educação, Universidade Federal Fluminense, Niterói, 2014.

BAKHTIN, Mikhail. Estética da Criação Verbal. São Paulo: Martins Fontes, 2003.

BENJAMIN, Walter, Magia e técnica, arte e política. São Paulo: Brasiliense, 1985.

BOURDIEU, Pierre. O poder Simbólico. Rio de Janeiro: Bertrand Brasil, 2000.

DIAS Belidson, IRWIN Rita L. (Org.). Pesquisa educacional baseada em arte, A/r/tografia. Santa Maria: Editora UFSM, 2013.

GÓMEZ MORENO, Pedro Pablo; MIGNOLO, Walter. Estéticas decoloniales [recurso electrónico]. Bogotá: Universidad Distrital Francisco José de Caldas, 2012.
LEVY, Pierre. As tecnologias da inteligência, o futuro do pensamento. Rio de Janeiro: Ed. 34, 1993.

MARIÁTEGUI, José Carlos. Temas de Nuestra América. Lima: Biblioteca Amauta, 1990.

MARIÁTEGUI, José Carlos. El artista y la época. Lima: Biblioteca Amauta, 1990a.

MARTÍN-BARBERO. Jesús. Dos meios às mediações, comunicação, cultura e hegemonia. Rio de Janeiro: Editora UFRJ, 1997.

MARTÍN-BARBERO. Jesús. Oficio de cartógrafo. São Paulo: Edições Loyola, 2004.

MIGNOLO, Walter. Geopolítica de la sensibilidad y del conocimiento, Sobre (de)colonialidad, pensamiento fronterizo y desobediencia epistémica. In transversal 01/12: unsettling knowledges. Viena: EIPCP - European Institute for Progressive Cultural Policies, 2011. Disponível em http://eipcp.net/transversal/0112/mignolo/ es. Acessado em 20/01/2018.

MIGNOLO, Walter. Aiesthesis decolonial. Calle 14, v. 4, n. 4, 2010. Disponível em https://dialnet.unirioja.es/descarga/articulo /3231040.pdf

MIGNOLO, Walter. Os esplendores e as misérias da 'ciência': colonialidade, geopolítica do conhecimento e pluri-versalidade epistémica. In SANTOS, Boaventura de Sousa (Ed.). Conhecimento prudente para uma vida decente: um discurso sobre as 'ciências' 
revistado. Lisboa: Edições Afrontamento, 2003, p. 631-671.

QUIJANO, Anibal. Colonialidad del poder y clasificación social. Journal of World Systems Research, v. 6, n. 2, p. 342-386, 2000.

QUIJANO, Anibal. Colonialidad del poder, cultura y conocimiento. In MIGNOLO, Walter (Comp.). Capitalismo y geopolítica del conocimiento - el eurocentrismo y la... Buenos Aires: Ed. Del Signo, 2001.

QUIJANO, Aníbal; WALLERSTEIN, Immanuel. Americanity as a Concept or the Americas in the Modern World System. International Journal of Social Sciences, Paris (UNESCO), n. 134, 1992.

SANTIAGO, Silviano. O entre-lugar do discurso latino-americano. In Uma leitura dos trópicos. São Paulo: Editora Perspectiva, 1978, p. 11-28.

SANTOS, Boaventura de S.; MENESES, Maria Paula (Org.). Epistemologias do Sul. Rio de Janeiro: Cortez Editora, 2010.0

SANTOS, Milton. O lugar: encontrando o Futuro. Revista de Urbanismo e Arquitetura, UFBA, v. 4, n. 1, p. 6-39, 1996. Disponível em https://www.portalseer.ufba.br/index .php/rua/article/view/3113. Acessado pela última vez em 20/12/2017.

SANTOS, Milton. A natureza do espaço: técnica e tempo, espaço e emoção. São Paulo: Hucitec, 1997.
SPIVAK, Gayatri C. Pode o subalterno falar? Belo Horizonte: Editora UFMG, 2010.

TORRES RIBEIRO, Ana Clara. Outros territórios, outros mapas.OSAL: Observatorio Social de América Latina, Buenos Aires (CLACSO), v. 6, n. 16, jun. 2005. 